\title{
BMJ Potentially preventable complications OPen of urinary tract infections, pressure areas, pneumonia, and delirium in hospitalised dementia patients: retrospective cohort study
}

\author{
Kasia Bail, ${ }^{1}$ Helen Berry, ${ }^{2}$ Laurie Grealish, ${ }^{1}$ Brian Draper, ${ }^{3}$ Rosemary Karmel, ${ }^{4}$ \\ Diane Gibson, ${ }^{1}$ Ann Peut ${ }^{5}$
}

To cite: Bail K, Berry $\mathrm{H}$, Grealish L, et al. Potentially preventable complications of urinary tract infections, pressure areas, pneumonia, and delirium in hospitalised dementia patients: retrospective cohort study. BMJ Open 2013;3:e002770. doi:10.1136/bmjopen-2013002770

- Prepublication history and additional material for this paper is available online. To view these files please visit the journal online (http://dx.doi.org/10.1136/ bmjopen-2013-002770).

\section{- Additional material is published online only. To view please visit the journal online (http://dx.doi.org/10. 1136/bmjopen-2013- 002770).}

Received 21 February 2013 Revised 8 May 2013

Accepted 8 May 2013

This final article is available for use under the terms of the Creative Commons Attribution Non-Commercial 2.0 Licence; see http://bmjopen.bmj.com

For numbered affiliations see end of article.

Correspondence to Dr Kasia Bail; kasia.bail@ canberra.edu.au

\section{ABSTRACT}

Objectives: To identify rates of potentially preventable complications for dementia patients compared with non-dementia patients.

Design: Retrospective cohort design using hospital discharge data for dementia patients, case matched on sex, age, comorbidity and surgical status on a $1: 4$ ratio to non-dementia patients.

Setting: Public hospital discharge data from the state of New South Wales, Australia for 2006/2007.

Participants: 426276 overnight hospital episodes for patients aged 50 and above (census sample).

Main outcome measures: Rates of preventable complications, with episode-level risk adjustment for 12 complications that are known to be sensitive to nursing care.

Results: Controlling for age and comorbidities, surgical dementia patients had higher rates than nondementia patients in seven of the 12 complications: urinary tract infections, pressure ulcers, delirium, pneumonia, physiological and metabolic derangement (all at $\mathrm{p}<0.0001$ ), sepsis and failure to rescue (at $\mathrm{p}<0.05)$. Medical dementia patients also had higher rates of these complications than did non-dementia patients. The highest rates and highest relative risk for dementia patients compared with non-dementia patients, in both medical and surgical populations, were found in four common complications: urinary tract infections, pressure areas, pneumonia and delirium.

Conclusions: Compared with non-dementia patients, hospitalised dementia patients have higher rates of potentially preventable complications that might be responsive to nursing interventions.

\section{INTRODUCTION}

Rates of adverse events remain a steadfast indicator of quality and safety for public hospitals. ${ }^{1}$ Older people are known to be particularly vulnerable to complications, with a Canadian

\section{ARTICLE SUMMARY}

Article focus

- Dementia patients are vulnerable to complications of hospitalisation, which contributes to increased length of stay, mortality and higher rates of transfer to residential care.

- The extent to which specific potentially preventable complications occur for dementia patients has not been elucidated.

- This article establishes rates of preventable complications for 12 complications that are known to be sensitive to nursing care.

Key messages

- Hospitalised dementia patients have much higher rates of potentially preventable complications, particularly urinary tract infections, pressure ulcers, pneumonia and delirium, than do hospitalised non-dementia patients.

- These complications are known to be responsive to nursing care.

- Further exploration of the role of nursing in preventing these complications in dementia patients is warranted.

Strengths and limitations of this study

- Study strengths include: an internationally established coding rule for patient-level risk adjustment; a linked administrative data approach which captures any person with documented dementia in a hospital episode over a 2-year period; an extremely large and representative sample, and a broad age range including patients aged 50 and above.

- The study is limited to one Australian jurisdiction (New South Wales, Australia's largest state), and has the usual limitations of hospital administrative data for the documentation of diagnoses.

study finding that $14 \%$ of older adults experienced an adverse event while in hospital. ${ }^{2}$ In an Australian study, complications such as 
urinary tract and respiratory infections, altered mental state, electrolyte disorders and pressure ulcers were more common in patients aged over 70 years. ${ }^{3}$ Factors that might contribute to this include multiple chronic diseases, longer hospitalisations, ${ }^{45}$ more frequent use of invasive devices, such as urinary catheters, ${ }^{6}$ more complicated diseases, less physiological reserve, an increased risk of falls and fractures, ${ }^{7}$ and atypical presentations of illness. ${ }^{8}$

There has been limited research into complications in dementia patients in hospital, ${ }^{5}$ but a systematic review found that dementia patients are older, require more hours of nursing care, have longer hospital stays and are more at risk of delayed discharge and functional decline during admission. ${ }^{6}$ To date, most study cohorts have been recruited from medical wards. ${ }^{6}$ In a Taiwanese retrospective cohort study, $\mathrm{Hu}$ et at found that dementia patients who underwent surgery had a significantly higher overall postoperative complication rate and also a higher incidence of postoperative complications that were less likely to be identified in their initial stage. These included acute renal failure, pneumonia, septicaemia, stroke and urinary tract infection. These potentially preventable complications have been demonstrated to be sensitive to nursing - that is, associated with modifiable characteristics of the nursing work environment, such as registered nurse skill mix and nurse burnout-in both Europe ${ }^{10}$ and America. ${ }^{11}$ More information regarding the rates of potentially preventable complications, which may be sensitive to nursing care for hospitalised dementia patients to confirm these findings internationally, would be useful for decisions related to resource allocation in healthcare.

\section{METHODS}

This study was nested in the Australian Hospital Dementia Services Project ${ }^{12}$ using New South Wales (NSW) hospital discharge data from the 2006/2007 financial year for all public hospital overnight discharges (less than 90 days' length of stay) for episodes of care for people aged 50 and over. An episode of hospital care may be defined as a period in a particular hospital of a particular care type (eg, acute or rehabilitation) in a particular hospital. A hospital stay is the period from admission into the hospital system to discharge from the system, or death in the hospital (eg, may include multiple care types and/or hospitals).

Consequently, a stay in hospital may include several episodes of care: on average, there were 1.18 episodes per stay. ${ }^{13}$ Dementia patients were identified via a person identifier as ever having dementia documented as a principal or additional diagnosis in any hospital stay over a 2-year period, offering a high capture rate and minimising selection bias. ${ }^{13}$ NSW is Australia's most populous state with a diverse population from metropolitan to remote areas and a range of hospital-based and/ or community-based dementia services. In 2007, 942100 people or $13.7 \%$ of NSW residents were aged 65 years and over. ${ }^{14}$ Consequently, NSW provides both system and population diversity.

Dementia patients were case matched on age group, sex, surgical status and Charlson comorbidities on a ratio of one dementia patient to four non-dementia patients. The Charlson index is widely used to limit the confounding influence of comorbidities on the prediction of 1-year mortality. ${ }^{15}$ The index accounts for diabetes, hemiplegia or paraplegia, any cancer, HIV/AIDS and major cardiovascular, renal, rheumatic, peptic ulcer and liver diseases and its predictive validity in older people is comparable to that of a self-report. ${ }^{16}$ Dementia is usually also included in Charlson indexing but was excluded for the purpose of comorbidity matching in this study. Where there were insufficient controls to achieve four nondementia patients for each dementia patient, 'bootstrapping' was utilised, where matching controls were randomised and then used more than once. This maximises the use of the existing population of cases and controls and maintains the benefits at a ratio of $1: 4 .^{17}$ This procedure was primarily necessary in the $85+$ age group.

Using internationally valid patient-level and risk-adjusted 'coding rules for adverse outcomes ${ }^{18-20}$ (see table 1), 12 potentially preventable complications sensitive to nursing care were examined. These coding rules have been used in Australia, New Zealand, Belgium and the USA over the last 20 years and also been translated from the International Classification of Diseases, Ninth Edition (ICD-9) to ICD-10. ${ }^{19}$ Patients are grouped according to medical or surgical status using the Australian Refined Diagnosis Related Groups (AR-DRGs) V5.2 code, which incorporates the ICD, Tenth Edition, Australian Modification (ICD-10-AM) 5th Edition, ${ }^{21}$ where surgery is inclusive of 'other' procedures such as gastroscopy and intubation. The coding rules utilise administrative data to exclude patients who are at risk of developing a particular condition due to their underlying aetiology. In this way, the episodes of complications examined are less likely to have occurred from patient risk, and more likely to be related to hospitalisation. For example, patients who have paralysis as a primary or secondary diagnosis are less mobile than other patients and are therefore excluded from the complication 'pressure ulcer'; patients with a primary or secondary diagnosis of any kidney or bladder condition are excluded from the complication 'urinary tract infection'. Consequently, each complication has a different sample size, based on exclusions and inclusions. Surgical and medical cohorts are analysed separately.

The statistical package SAS EG V.9.2 was used. Pearson's $\chi^{2}$ test of independence demonstrated the magnitude of association and goodness-of-fit of the relative risk (RR) between dementia and non-dementia patients, where RR was calculated using the residuals adjusted for sample size and the 1:4 case-to-control ratio. Missing data were rare in the variables used in this analysis. Diagnosis information was missing in less than $0.2 \%$ and sex in less than $0.001 \%$ of records for 2006 2007; AR-DRGs data were always present. The dataset 
Table 1 Coding rules for adverse outcomes (only 4 of the 12 complications shown for readability)

\begin{tabular}{|c|c|}
\hline Complication & $\begin{array}{l}\text { Inclusion criteria } \\
\text { Any secondary diagnosis of }\end{array}$ \\
\hline $\begin{array}{l}\text { Urinary tract } \\
\text { infection }\end{array}$ & $\begin{array}{l}\text { Urinary tract infection, non-specified site } \\
\text { Infection and inflammatory reaction due to implant } \\
\text { prosthesis and graft in urinary system }\end{array}$ \\
\hline Pressure ulcer & Decubitus ulcer and pressure area \\
\hline Pneumonia & $\begin{array}{l}\text { Pneumonitis due to solids and liquids } \\
\text { Post procedure respiratory disorder, unspecified } \\
\text { Other post procedural respiratory disorders } \\
\text { Hypostatic pneumonia, unspecified } \\
\text { Pneumonia, haemophilus influenza and bacterial } \\
\text { pneumonia } \\
\text { Other bacterial pneumonia } \\
\text { Bacterial pneumonia, unspecified } \\
\text { Bronchopneumonia, unspecified } \\
\text { Other pneumonia, organism unspecified } \\
\text { Pneumonia, unspecified }\end{array}$ \\
\hline
\end{tabular}

\section{Exclusion criteria \\ Any primary diagnosis or major diagnostic category (MDC) of}

Urinary tract infection, non-specified site

Infection and inflammatory reaction due to implant, prosthesis and graft in urinary system

Streptococcal sepsis, other sepsis

Bacterial infection, unspecified

Kidney and urinary tract (MDC)

Female reproductive system (MDC)

Pregnancy, childbirth and puerperium (MDC)

Newborn and other neonates (perinatal period; MDC)

Any primary or secondary diagnosis of:

Pregnancy

Abortion

Decubitus ulcer and pressure area

Skin, subcutaneous tissue and breast (MDC)

Any primary or secondary diagnosis of:

Hemi/quadriplegia

Viral pneumonia, not elsewhere classified

Pneumonia due to Streptococcus pneumoniae

Bacterial pneumonia due to flu

Other bacterial pneumonia

Bacterial pneumonia, unspecified

Pneumonia due to Mycoplasma pneumoniae

Due to other infectious organisms

In diseases classified elsewhere

Bronchopneumonia, unspecified

Other pneumonia, organism unspecified

Pneumonia, unspecified

Influenza

Influenza, virus not identified

Pneumonitis due to food and vomit

Postprocedural respiratory disorder, unspecified

Other postprocedural respiratory disorders

Hypostatic pneumonia, unspecified

Respiratory system (MDC)Any primary or

secondary diagnosis of:

Immunodeficiency

Systemic autoimmune disease, unspecified

HIV

Coma, unspecified

Stupor, semi-coma

Delirium, unspecified

Delirium, unspecified

Other specified dissociative (conversion) disorders

Adjustment disorders

Other specified dissociative (conversion) disorders

Adjustment disorders

Reaction to severe stress, unspecified

Reaction to severe stress, unspecified

Nervous system (MDC)

Mental diseases and disorders (MDC)

Alcohol/drug use or induced mental disorders (MDC)

MDC, major diagnostic category.

was extracted from the source administrative data based on age $(50+)$, and therefore patient age is never missing in this analysis. Owing to the very low level of missing data, records with missing information were excluded from the analysis where relevant.

\section{RESULTS}

There were $44488(10.44 \%)$ hospital episodes for dementia patients in NSW over the period 2006-2007, compared with 381788 for non-dementia patients. Surgery was much less common in dementia patients 
(12\%) than in non-dementia patients (27\%). The average surgical dementia patient age was 81 with a Charlson index of 1.04 (indicating that most dementia patients had one comorbidity in addition to dementia), whereas the average surgical non-dementia patient age was 68 with a lower Charlson index of 0.89. Dementia patients had more hospital episodes with potentially preventable complications than did non-dementia patients, and this difference was higher in the surgical population.

Table 2 shows the results for medical and surgical patients. Medical dementia patients (ie, those who did not undergo surgery) had higher rates of delirium (RR 2.83), urinary tract infections (RR 1.79), pressure ulcers (RR 1.61), pneumonia (RR 1.37; all at $\mathrm{p}<0.0001$ ), as well as sepsis (RR 1.34) and failure to rescue (death following sepsis, shock, gastrointestinal bleeding, deep vein thrombosis or pneumonia; RR 1.24; at $\mathrm{p}<0.05$ ), compared with non-dementia patients. There was no significant difference between medical dementia and non-dementia patients for shock or gastrointestinal bleeding. Deep vein thrombosis/pulmonary embolism was the only complication found to be significantly less common in dementia patients (RR 0.82; at $\mathrm{p}<0.05$ ).

Surgical dementia patients had higher rates of delirium (RR 3.10), urinary tract infections (RR 2.88), pressure ulcers (RR 1.84), pneumonia (RR 1.66) and physical or metabolic derangement (serous fluid and/or electrolyte imbalance; RR 1.87; all at $\mathrm{p}<0.0001)$, as well as gastrointestinal bleeding ( $R R$ 1.68; $p<0.05)$, compared with non-dementia patients. There was no significant difference in the rates of sepsis, shock, surgical wound infection, pulmonary failure or failure to rescue in dementia patients compared with non-dementia patients.

Compared with medical dementia patients, surgical dementia patients had significantly higher RRs (at $\mathrm{p}<0.05)$ of urinary tract infections ( $R R \quad 1.09$ ), pressure ulcers (RR 1.24) and pneumonia (RR 1.42), but not of delirium. In non-dementia patients, medical patients were more likely than surgical patients to get a urinary tract infection (RR 0.71; at $\mathrm{p}<0.0001$ ); there were no other significant differences. Dementia was consequently a more informative indicator of risk of preventable complications than was surgery for these four common complications. Separately, while noting that dementia patients were much less likely than non-dementia patients to undergo surgery, the surgical procedures carried out showed more risk of preventable complications for dementia patients than for non-dementia patients.

The strongest findings of the study (at $\mathrm{p}<0.0001$ ), with the greatest differences in rates of dementia and nondementia patients, for surgical and medical cohorts, were related to four common complications: urinary tract infections, pressure ulcers, pneumonia and delirium. Fourteen per cent of surgical dementia patients suffered from urinary tract infections while in hospital, which was 2.8 times higher than for surgical non- dementia patients. Seven per cent suffered from pressure ulcer, 1.84 times higher than for non-dementia patients. Seven per cent also suffered from pneumonia, 1.66 times the rate for non-dementia patients and 5\% suffered delirium, which was 3.1 times higher than for non-dementia patients. These infections and complications were not likely to be related to the person's admitted diagnosis; thus, they were more likely to be nosocomial or hospital acquired and therefore potentially preventable.

\section{DISCUSSION}

These findings demonstrate that hospitalised dementia patients have higher rates of complications than hospitalised non-dementia patients, controlling for current comorbidities, and that these rates of complications are significantly higher in dementia patients who have surgery. These findings support previous nationwide, cohort designed Taiwanese findings that dementia patients have higher rates of postoperative complications than non-dementia patients at the hospital episode level. ${ }^{9}$ The highest rates and highest RRs for dementia patients, for both medical and surgical patients, are for urinary tract infections, pressure ulcers, delirium and pneumonia. This new finding of high rates for four very common preventable complications for dementia patients offers avenues for intervention and prevention.

We note that, compared with hospitalised people who do not have dementia, those with dementia are slightly more likely to have multiepisode stays $(87 \%$ vs $82 \%)$; they are much more likely to be readmitted within 3 months of discharge ( $45 \%$ vs $32 \%)$ and average more stays over the year (2.5 vs 1.9; calculations derived from ref. 12). Having dementia may therefore bias estimates of rates of preventable complications (primarily upwards). However, sensitivity testing, not reported here, indicated that, adjusting for sex, age and different patterns of hospital stays, all comparisons that showed significant differences in risk ratios for people with dementia in our original analyses remained significant in the adjusted analyses (and at the same $\mathrm{p}$ value level). The effect of dementia on the likelihood of developing avoidable complications was robust. Nevertheless, future data collection planning should directly include information about the number of episodes per stay, number of rapid readmissions and number of stays per year.

Three key design features of this new Australian study give additional credibility to the findings: (1) the comprehensive linked approach over 2 years of administrative data to better identify dementia patients, ${ }^{13}$ (2) the patient-level risk-adjustment model to better capture in-hospital complications ${ }^{18}$ and (3) the inclusion of 50 -year-olds to 65-year-olds with dementia who are known to have different characteristics from other aged populations. ${ }^{5}$

Evidence is mounting for associations between poorer nursing work environments and higher rates of patient 
Table 2 Population, samples, percentage rates and relative risks of potentially preventable complications in the over 50 age group from NSW public hospital episode data 2006-2007

\begin{tabular}{|c|c|c|c|c|c|c|c|c|c|}
\hline \multirow[b]{3}{*}{ Preventable complication } & \multirow[b]{3}{*}{ Patient population } & \multicolumn{4}{|c|}{$\begin{array}{l}\text { Percentage of patient episodes with the } \\
\text { complication } \dagger\end{array}$} & \multicolumn{4}{|c|}{$\begin{array}{l}\text { Relative risk of dementia patients with the complication compared } \\
\text { with non-dementia patients } \neq\end{array}$} \\
\hline & & \multicolumn{2}{|l|}{ Medical } & \multicolumn{2}{|c|}{ Surgical } & \multicolumn{2}{|l|}{ Medical } & \multicolumn{2}{|c|}{ Surgical } \\
\hline & & Sample & Per cent & Sample & Per cent & Sample & $\mathrm{RR}(\mathrm{Cl})$ & Sample & RR (Cl) \\
\hline \multirow[t]{3}{*}{ Urinary tract infection } & Dementia & 36075 & 13.4 & 4854 & 14.7 & $58223 \S$ & $1.79^{\star \star}(1.70$ to 1.90$)$ & 7680 & $2.88^{\star \star}(2.45$ to 3.40$)$ \\
\hline & Non-dementia & 146813 & 7.9 & 18986 & 5.6 & & & & \\
\hline & All $>50$ & 182888 & 9.0 & 23840 & 7.4 & & & & \\
\hline \multirow[t]{3}{*}{ Pressure ulcer } & Dementia & 25832 & 5.9 & 4007 & 7.3 & 38480 & $1.61^{\star *}$ (1.46 to 1.77$)$ & 5904 & $1.84^{\star *}(1.46$ to 1.31$)$ \\
\hline & Non-dementia & 89074 & 3.8 & 13493 & 4.1 & & & & \\
\hline & All $>50$ & 114906 & 4.2 & 17500 & 4.9 & & & & \\
\hline \multirow{3}{*}{ Pneumonia } & Dementia & 36875 & 4.8 & 5106 & 6.8 & 59523 & $1.37^{\star \star}(1.26$ to 1.48$)$ & 8184 & $1.66^{\star \star}(1.36$ to 2.02$)$ \\
\hline & Non-dementia & 150118 & 3.5 & 20497 & 4.2 & & & & \\
\hline & All $>50$ & 186993 & 3.8 & 25603 & 4.7 & & & & \\
\hline \multirow[t]{3}{*}{ Deep vein thrombosis } & Dementia & 39104 & 0.8 & 5154 & 1.4 & 62459 & $0.82^{*}(0.69$ to 0.97$)$ & 8245 & $1.14(0.78$ to 1.68$)$ \\
\hline & Non-dementia & 155882 & 1.0 & 20609 & 1.2 & & & & \\
\hline & All $>50$ & 194986 & 0.9 & 25763 & 1.2 & & & & \\
\hline \multirow{3}{*}{ Gastrointestinal bleeding } & Dementia & 30035 & 1.1 & 2702 & 3.8 & 50246 & $1.01(0.85$ to 1.19$)$ & 5405 & $1.68^{*}(1.22$ to 2.31$)$ \\
\hline & Non-dementia & 131088 & 1.1 & 16215 & 2.3 & & & & \\
\hline & All $>50$ & 161123 & 1.1 & 18917 & 2.5 & & & & \\
\hline \multirow[t]{3}{*}{ Sepsis } & dementia & 25365 & 1.9 & 4469 & 10.6 & 39218 & $1.34^{*}(1.15$ to 1.57$)$ & 6595 & 1.25 (0.96 to 1.64$)$ \\
\hline & Non-dementia & 94631 & 1.4 & 15100 & 3.1 & & & & \\
\hline & All $>50$ & 119996 & 1.6 & 19569 & 4.9 & & & & \\
\hline \multirow[t]{3}{*}{ Shock and cardiac arrest } & Dementia & 31021 & 0.6 & 2793 & 1.3 & 51256 & 1.09 (0.86 to 1.37$)$ & 5521 & 0.93 (0.58 to 1.50$)$ \\
\hline & Non-dementia & 132194 & 0.5 & 16431 & 1.3 & & & & \\
\hline & All $>50$ & 163215 & 0.6 & 19224 & 1.3 & & & & \\
\hline \multirow[t]{3}{*}{ Delirium } & Dementia & 37933 & 4.0 & 5155 & 4.4 & 61307 & $2.83^{\star \star}(2.54$ to 3.15$)$ & 8251 & $3.10^{\star \star}(2.31$ to 4.15$)$ \\
\hline & Non-dementia & 154805 & 1.5 & 20636 & 1.5 & & & & \\
\hline & All >50 & 192738 & 2.0 & 25791 & 2.1 & & & & \\
\hline \multirow[t]{3}{*}{ Surgical wound infection§ } & Dementia & - & - & 5158 & 0.1 & - & - & 8253 & $1.12(0.48$ to 2.63$)$ \\
\hline & Non-dementia & - & - & 20633 & 0.0 & & & & \\
\hline & All $>50$ & - & - & 25791 & 0.0 & & & & \\
\hline \multirow[t]{3}{*}{ Pulmonary failure§ } & Dementia & - & - & 2870 & 2.0 & - & - & 5628 & $0.98(0.81$ to 1.19$)$ \\
\hline & Non-dementia & - & - & 16660 & 1.7 & & & & \\
\hline & All $>50$ & - & - & 19530 & 1.7 & & & & \\
\hline \multirow{3}{*}{$\begin{array}{l}\text { Physiological/metabolic } \\
\text { derangement§,ף }\end{array}$} & Dementia & - & - & 2881 & 11.5 & - & - & 5644 & $1.87^{\star *}(1.55$ to 2.25$)$ \\
\hline & Non-dementia & - & - & 16699 & 6.5 & & & & \\
\hline & All $>50$ & - & - & 19580 & 7.3 & & & & \\
\hline \multirow{3}{*}{ Failure to rescuet† } & Dementia & 2597 & 28.2 & 561 & 22.3 & 3745 & $1.24^{*}(1.02$ to 1.33$)$ & 778 & $0.86(0.61$ to 1.20$)$ \\
\hline & Non-dementia & 8336 & 24.1 & 1647 & 25.0 & & & & \\
\hline & All $>50$ & 10933 & 25.1 & 2208 & 24.3 & & & & \\
\hline \multicolumn{10}{|c|}{$\begin{array}{l}{ }^{*} p<0.5 . \\
{ }^{* \star} p<0.0001 . \\
\dagger \text { Excluding precipitating pre-existing conditions for each complication. } \\
\text { fWeighted } 80-20 \% \text { to compensate for } 1: 4 \text { case-control ratio. } \\
\text { §These complications are only measured in a surgical population. } \\
\text { १Physiological and/or metabolic derangement are serous fluid and electrolyte imbalances. } \\
+† F a i l u r e \text { to rescue is death following sepsis, shock, gastrointestinal bleeding or pneumonia. } \\
\text { NSW, New South Wales; RR, relative risk. }\end{array}$} \\
\hline
\end{tabular}


Table 3 Evidence of association between the four key complications and nursing work environments

\begin{tabular}{|c|c|c|c|c|}
\hline Study & Sample & $\begin{array}{l}\text { Location and data } \\
\text { time frame }\end{array}$ & $\begin{array}{l}\text { Characteristics of nursing work environments } \\
\text { (independent variable) }\end{array}$ & $\begin{array}{l}\text { Patient complication } \\
\text { (dependent variable) }\end{array}$ \\
\hline Cimiotti $^{22}$ & $\begin{array}{l}161 \text { hospitals } \\
1571068 \text { patients } \\
7076 \text { nurses }\end{array}$ & USA 2006 & Lower levels of burnt out (a) nurses & Lower rates of urinary tract infection \\
\hline Needleman et $a l^{18}$ & $\begin{array}{l}799 \text { hospitals } \\
6 \text { million+ patients }\end{array}$ & USA 1997 & Higher levels of total nurse staffing & Lower rates of urinary tract infection \\
\hline Cho et $a^{3}$ & $\begin{array}{l}232 \text { hospitals } \\
124204 \text { patients }\end{array}$ & USA 1997 & Higher proportions of RNs (b) & Lower rates of pneumonia \\
\hline Kovner et $a{ }^{24}$ & 187 hospitals & USA $1990-1996$ & Higher RN hours per patient day & Lower rates of pneumonia \\
\hline Pappas et $a^{25}$ & $\begin{array}{l}2 \text { hospitals } \\
3200 \text { patients }\end{array}$ & USA 2007 & Higher RN hours per patient day & Lower rates of pneumonia \\
\hline Kane et al ${ }^{11}$ & $\begin{array}{l}\text { Systematic review } \\
96 \text { studies }\end{array}$ & USA 2006 & Higher proportions of $\mathrm{RN}$ per patient day & $\begin{array}{l}\text { Decreased OR of hospital-acquired } \\
\text { pneumonia }\end{array}$ \\
\hline Twigg et $a^{26}$ & $\begin{array}{l}3 \text { hospitals } \\
236454 \text { patients } \\
150925 \text { nurses }\end{array}$ & Australia 2000-2004 & Refined staffing model (c) & $\begin{array}{l}\text { Lower rates of pneumonia Lower rates } \\
\text { of delirium }\end{array}$ \\
\hline Schubert et $a$ P $^{7}$ & $\begin{array}{l}8 \text { hospitals } \\
779 \text { patients } \\
1338 \text { nurses }\end{array}$ & Switzerland 2003-2004 & Implicit care rationing $(d)$ & $\begin{array}{l}\text { Predicted higher levels of pressure } \\
\text { ulcers }\end{array}$ \\
\hline Horn et $a^{28}$ & $\begin{array}{l}82 \text { RACF } \\
1376 \text { residents }\end{array}$ & USA 1996-1997 & Higher RN direct time per resident per day & Lower rates of pressure ulcers \\
\hline Pekkarinen et $a$ P $^{9}$ & $\begin{array}{l}66 \text { RACF } \\
724 \text { nurses }\end{array}$ & Finland 2002 & Increased time unit pressure $(\mathrm{e})$ & Higher rates of pressure ulcers \\
\hline Hickey et $a \beta^{30}$ & $\begin{array}{l}35 \text { RACF } \\
\text { Patient assessment } \\
\text { files } \\
\text { Staffing data }\end{array}$ & USA 1998-1999 & Lower skill mix (less RNs) & Higher rates of pressure ulcers \\
\hline \multicolumn{5}{|c|}{$\begin{array}{l}\text { (a) Burnt out: where workers emotionally and cognitively detach from work as a way to cope with demands. } \\
\text { (b) RN: registered nurse-a graduate from a University or college nursing programme who has met national licensing conditions. } \\
\text { (c) Refined staffing model: which developed categories of nurse staffing based on patient complexity, intervention levels, high dependency beds, emergency/elective patient mix and patient } \\
\text { turnover. } \\
\text { (d) Implicit care rationing: where nurses withhold or fail to carry out necessary nursing tasks due to inadequate time, staffing level and/or skill mix. } \\
\text { (e) Time unit pressure: as a measure of nursing working conditions. } \\
\text { RACF, residential aged care facility. }\end{array}$} \\
\hline
\end{tabular}


complications (see table 3) and demonstrates that, for the four key complications found for dementia patients in the present study, these complications may be modifiable. Nursing interventions, with and without direct medical personnel involvement, for preventing or mitigating these common complications involve mobility, hydration, hygiene, patient education and reassurance in a context of nursing surveillance, assessment, early intervention and advocacy. Nurses, more than any other healthcare professional, are able to recognise, interrupt, evaluate and correct healthcare errors. ${ }^{31}$ Specifically, in relation to urinary tract infections, it is argued that higher levels of engaged and educated nurses better enable sterile techniques for catheter insertion, timeconsuming toileting programmes and management of hygiene and hydration. ${ }^{20} 32$ In relation to pneumonia, nurses are responsible for (or at least instrumental in) many of the necessary clinical practices, such as encouraging flu vaccination, hand washing, pain relief, mobilisation and pulmonary hygiene for reducing pneumonia. ${ }^{32}$ In relation to delirium, simple preventative measures, such as verbal reorientation, correcting sensory deficits, improving mobilisation, improving hydration, decreased use of sleeping and psychoactive medications and restraints, ${ }^{33}$ are initiated, maintained and reinforced by nurses in acute settings. In relation to pressure areas, patient positioning and skin care are the primary domain of nurses more than any other profession, and their actions in relation to hydration, nutrition, mobility and pain relief are also accepted as having a significant impact on the prevention of pressure ulcers. ${ }^{34}$ The development of complications can be set in motion by a seemingly innocuous first event (eg, a urinary tract infection can develop from dehydration, which can start with something as simple as a missed cup of morning tea). This has been termed 'cascade iatrogenesis' and is a helpful concept in understanding the link between unmet nursing care needs and potentially preventable complications. ${ }^{35} 36$

These findings highlight the need to view nursing as an intervention rather than as a labour cost in terms of the nursing work environment's impact on patient outcomes. Despite hospitals spending approximately one-third of their budget on ward nursing, ${ }^{37}$ "administrative datasets have not been designed to capture a great deal of information about nurses." ${ }^{\text {"2 }}$ Staffing data in Australia are limited to hospital level aggregate data for a whole year, without differentiation of types of nurses (eg, registered nurse or unlicensed personnel), or state level data by the nurse's postcode of residence. Better hospital nursing data would enable research investigating associations between nurse staffing and patient outcomes, as well as opportunities for systemic benchmarking. 9 38 The USA has a more systemic approach to data collection in relation to nursing care but many of the data items are restricted to specific locations (eg, intensive care units). Recommendations have been made that the minimum datasets in America be expanded so that urinary tract infections and pneumonia are measured in all at-risk hospitalised patients. ${ }^{32}$ The present study would support this policy. We would also suggest that future acute dementia care intervention studies consider controlling for relevant nursing characteristics.

The four key complications identified here have some of the highest dollar costs for hospitals. For example, though urinary tract infections and pneumonia have relatively low per-case costs, their large volume means that they have the greatest system financial impact in Australia. ${ }^{3}$ If we want to reduce the cost and occurrence of preventable complications in hospitalised dementia patients, we need to better understand the relationships between nursing work environments and patient outcomes. In order to increase this understanding, we need better data collection strategies for quality benchmarking and research. These data collection strategies need to include (1) screening and documentation of dementia patients in hospital, (2) minimum nursing work environment characteristics, such as appropriate ratios of registered nurse staffing and skill mix and management of workload/pressure and burnout/retention, and (3) rates of the common in-hospital complications of urinary tract infections, pressure ulcers, pneumonia and delirium, and not just as secondary diagnoses.

\section{CONCLUSION}

Dementia patients have higher rates of potentially preventable complications while in hospital than do nondementia patients, even when controlling for age, sex, surgery and comorbidities. The highest rates and largest differences in rates, for dementia patients compared with non-dementia patients, are seen in urinary tract infections, pneumonia, pressure ulcers and delirium. These complications have been specifically associated with aspects of nursing work environments, including staffing skill mix of registered nurses, and workload measures, such as burnout and time pressure. Modifying aspects of the nursing work environment may reduce or prevent these complications in hospitalised dementia patients (and, indeed, in other patients). Improving hospital data collection strategies for the identification of dementia patients and key nursing characteristics would enable benchmarking and research in order to improve the care, and cost of care, for this burgeoning population.

\footnotetext{
Author affiliations

${ }^{1}$ Faculty of Health, University of Canberra, Canberra, Australian Capital Territory, Australia

${ }^{2}$ Centre for Research and Action in Public Health, The University of Canberra, Canberra, Australian Capital Territory, Australia

${ }^{3}$ University of New South Wales, Academic Department for Old Age Psychiatry, Euroa Centre, Prince of Wales Hospital, Randwick, New South Wales, Australia

${ }^{4}$ Data Linkage Unit, Australian Institute of Health and Welfare, Canberra, Australian Capital Territory, Australia

${ }^{5}$ Ageing and Aged Care, Australian Institute of Health and Welfare, Canberra, Australian Capital Territory, Australia
} 
Contributors DG, BD, RK and AP devised the idea of the Hospital Dementia Services study, designed the methods, raised the funding and conducted the analysis. KB was responsible for implementing the nested study reported here and carrying out all the analyses. HB and LG supervised this nested study. $\mathrm{HB}, \mathrm{RK}$ and $\mathrm{BD}$ provided statistical advice. KB prepared the first draft of the manuscript and all authors contributed to each section of the final draft of the manuscript. KB is guarantor.

Funding The Hospital Dementia Services Project was funded by the National Health and Medical Research Council (ID465701). DCRC provided a PhD scholarship to the first author.

Competing interests All authors have completed the Unified Competing Interests form at http://www.icmje.org/coi_disclosure.pdf (available on request from the corresponding author) and declare: KB was supported by a PhD Scholarship funded by the Dementia Collaborative Research CentreAssessment and Better Care, University of New South Wales as part of an Australian Government Initiative. Support has been received by the employing organisations from Alzheimer's Australia in regard to commissioned work using data collected in the course of the Hospital Dementia Services Project. No other declarations are made regarding other relationships or activities that could appear to have influenced the submitted work.

Ethics approval Obtained from the NSW Population and Health Services Research Ethics Committee (HREC/08/CIPHS/49 and 2008/11/109), the Australian Institute of Health and Welfare Ethics Committee, the University of NSW and the University of Canberra Human Research Ethics Committees (08-85).

Provenance and peer review Not commissioned; externally peer reviewed.

Data sharing statement Statistical code and technical appendix available from the corresponding author. Dataset inquiries can be made to the Australian Institute of Health and Welfare via the corresponding author.

\section{REFERENCES}

1. Australian Patient Safety Foundation. Iatrogenic injury in Australia. Adelaide, 2001.

2. Ackroyd-Stolarz S, Guernsey JR, MacKinnon NJ, et al. Adverse events in older patients admitted to acute care: a preliminary cost description. Healthc Manage Forum 2009;22:32-6.

3. Purpora C, Blegen MA. Horizontal violence and the quality and safety of patient care: a conceptual model. Nurs Res Pract 2012;2012:306948-52.

4. Lang PO, Zekry D, Michel JP, et al. Early markers of prolonged hospital stay in demented inpatients: a multicentre and prospective study. J Nutr Health Aging 2010;14:141-7.

5. Draper B, Karmel R, Gibson D, et al. The Hospital Dementia Services Project: age differences in hospital stays for older people with and without dementia. Int Psychogeriatr 2011;23:1649-58.

6. Mukadam N, Sampson EL. A systematic review of the prevalence, associations and outcomes of dementia in older general hospital inpatients. Int Psychogeriatr 2011;23:344-55.

7. Brennan TA, Leape LL, Laird NM, et al. Incidence of adverse events and negligence in hospitalised patients-results of the Harvard Medical Practice Study. N Engl J Med 1991;324:370-6.

8. Mitty E. latrogenesis, frailty, and geriatric syndromes. Geriatr Nurs 2010;31:368-74.

9. Hu C-J, Liao C-C, Chang C-C, et al. Postoperative adverse outcomes in surgical patients with dementia: a retrospective cohort study. World J Surg 2012;36:2051-8.

10. Aiken LH, Sermeus W, Van den Heede K, et al. Patient safety, satisfaction, and quality of hospital care: cross sectional surveys of nurses and patients in 12 countries in Europe and the United States. BMJ 2012;344:e1717.

11. Kane RL, Shamliyan TA, Mueller $\mathrm{C}$, et al. The association of registered nurse staffing levels and patient outcomes-systematic review and meta-analysis. Med Care 2007;45:1195-204.

12. Australian Institute of Health and Welfare. People with dementia in hospitals in New South Wales 2006-07. Canberra: AlHW, 2012.

13. Australian Institute of Health and Welfare. Deriving key patient variables: a technical paper for the Hospital Dementia Services project. Canberra: AlHW, 2012.
14. Australian Bureau of Statistics. Publication 3235.0—population by age and sex, regions of Australia, 2007, 2007.

15. Sundararajan V, Henderson T, Perry C, et al. New ICD-10 version of the Charlson comorbidity index predicted in-hospital mortality. J Clin Epidemiol 2004;57:1288-94.

16. Susser SR, McCusker J, Belzile E. Comorbidity information in older patients at an emergency visit: self-report vs. administrative data had poor agreement but similar predictive validity. J Clin Epidemiol 2008;61:511-15.

17. Wacholder S, Silverman DT, McLaughlin JK, et al. Selection of controls in case-control studies. 3. Design options. Am J Epidemiol 1992; 135:1042-50.

18. Needleman J, Buerhaus P, Potter V, et al. Nurse staffing and patient outcomes in hospitals. Nashville: Harvard School of Public Health, 2001.

19. McCloskey BA, Diers DK. Effects of New Zealand's health reengineering on nursing and patient outcomes. Med Care 2005;43:1140-6.

20. Duffield C, Roche M, O'Brien-Pallas L, et al. Glueing it together: Nurses, their work environment and patient safety. Sydney: University of Technology, 2007.

21. Department of Health and Ageing. Classifications: Australian Refined Diagnosis Related Groups (AR-DRGs). 2012.

22. Cimiotti. Nurse staffing, burnout, and health care-associated infection. Am J Infect Control 2012;40:486-90.

23. Cho SH, Ketefian S, Barkauskas VH, et al. The effects of nurse staffing on adverse events, morbidity, mortality, and medical costs. Nurs Res 2003;52:71-9.

24. Kovner C, Jones C, Zhan C, et al. Nurse staffing and postsurgical adverse events: an analysis of administrative data from a sample of US hospitals, 1990-1996. Health Serv Res 2002;37:611-29.

25. Pappas SH. The cost of nurse-sensitive adverse events. J Nurs Adm 2008;38:230-6.

26. Twigg D, Duffield C, Bremner A, et al. The impact of the nursing hours per patient day (NHPPD) staffing method on patient outcomes: a retrospective analysis of patient and staffing data. Int $J$ Nurs Stud 2010;48:540-8.

27. Schubert M, Glass TR, Clarke SP, et al. Rationing of nursing care and its relationship to patient outcomes: the Swiss extension of the International Hospital Outcomes Study. Int J Qual Health Care 2008;20:227-37.

28. Horn SD, Buerhaus $\mathrm{P}$, Bergstrom N, et al. RN staffing time and outcomes of long-stay nursing home residents-pressure ulcers and other adverse outcomes are less likely as RNs spend more time on direct patient care. Am J Nur 2005;105:58-70.

29. Pekkarinen L, Sinervo T, Elovainio M, et al. Drug use and pressure ulcers in long-term care units: do nurse time pressure and unfair management increase the prevalence? J Clin Nurs 2008;17:3067-73.

30. Hickey EC, Young GJ, Parker VA, et al. The effects of changes in nursing home staffing on pressure ulcer rates. J Am Med Dir Assoc 2004;6:50-3.

31. Rothschild JM, Hurley AC, Landrigan CP, et al. Recovery from medical errors: the critical care nursing safety net. Jt Comm J Qual Patient Saf 2006;32:63-72.

32. Naylor MD. Advancing the science in the measurement of health care quality influenced by nurses. Med Care Res Rev 2007:64:144S-69S

33. Inouye SK, Charpentier PA. Precipitating factors for delirium in hospitalized elderly persons-predictive model and interrelationship with baseline vulnerability. JAMA 1996;275:852-7.

34. Padula CA, Osborne E, Williams J. Prevention and early detection of pressure ulcers in hospitalized patients. J Wound Ostomy Continence Nurs 2008;35:65-75; discussion 76-8.

35. Rothschild JM, Bates DW, Leape LL. Preventable medical injuries in older patients. Arch Intern Med 2000;160:2717-28.

36. Thornlow DK, Anderson R, Oddone E. Cascade iatrogenesis: factors leading to the development of adverse events in hospitalized older adults. Int J Nurs Stud 2009;46:1528-35.

37. Watts J, Richardson J, Segal L. Comparing national public hospital cost data collections for use in performance reporting. In: TCfHP.ed Evaluation. Monash University, West Heidelberg Victoria, 2000:1-40.

38. Schilling P, Goulet JA, Dougherty PJ. Do higher hospital-wide nurse staffing levels reduce in-hospital mortality in elderly patients with hip fractures: a pilot study. Clin Orthop Relat Res 2011;469:2932-40. 